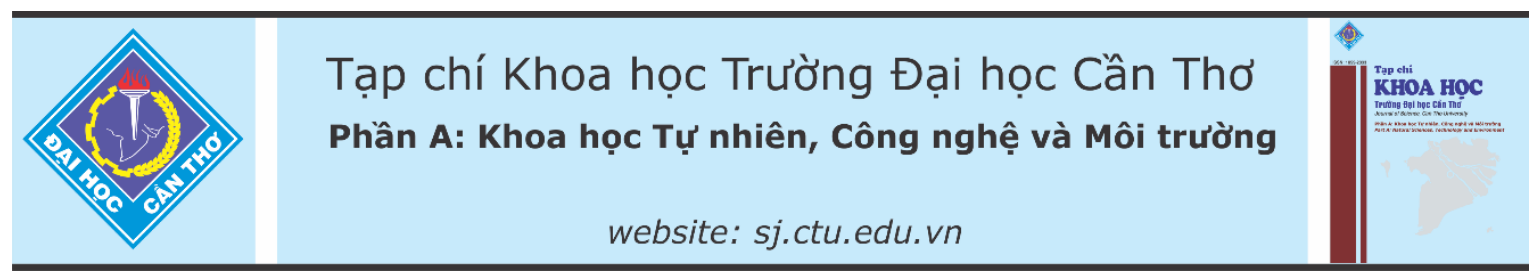

DOI:10.22144/ctu.jvn.2021.082

\title{
XÁC ĐỊ̂HH YẾU TỐ ẢNH HƯởNG ĐẾN QUY HOẠCH SỬ DƯNG ĐẤT ĐAI TRÊN ĐỊA BẦN THÀNH PHỐ CẦN THƠ THEO GÓC NHİ̀ NGƯỜi SỬ DỤNG ĐẤT
}

\author{
Nguyễn Minh Thông ${ }^{1}$ và Phan Trung Hiền ${ }^{2}$
}

${ }^{1}$ Ủy ban kiểm tra Thành ủy Cần Tho

${ }^{2}$ Khoa Luật, Trường Đại học Cần Tho

*Nguoòi chịu trách nhiệm về bài viết: Nguyễn Minh Thông (email: nguyenminhthongvn89@gmail.com)

\section{Thông tin chung:}

Ngày nhận bài: $30 / 04 / 2021$

Ngày nhận bài sủa: 29/05/2021

Ngày duyệt đăng: 25/06/2021

Title:

Factors affecting land use planning in Can Tho city from land users' point of view

\section{Tù khóa:}

Người sử dụng đất, phân tích nhân tố khám phá, quy hoạch sủ dụng đất, yếu tố ânh hưởng

\section{Keywords:}

Exploratory factor analysis, factors affecting, land use planning, land user

\begin{abstract}
The study was conducted to determine the factors that affect land use planning in Can Tho city based on the application of exploratory factor analysis model and multivariate linear regression model. The survey was conducted with 100 land users in Can Tho city. The result indicated that $55.1 \%$ of the variation of residential land use planning could be explained by the variation of the 5 groups of independent variables. The obtained results showed that five groups of factors affecting the land use planing in Can Tho city by land user perspective with the statistical significance of $1 \%$ (ranked from strong to weak) include group of economic factors, group of environmental factors, group of other factors, group of social factors, group of institutional and legal factors.
\end{abstract}

\section{TÓM TẮT}

Trong nghiên cứu này, mô hình phân tích nhân tố khám phá (exploratory factor analysis - EFA) và mô hình hồi quy tuyến tính đa biến được sủ dụng nhằm xác định các yếu tố ảnh hưởng đến quy hoạch sư dụng đất đai trên địa bàn thành phố Cần Tho. Thông qua thực hiện phỏng vấn điều tra với 100 nguoòi sủ dung đất trong vùng quy hoạch trên địa bàn thành phố Cần Tho, kết quả phân tích hồi quy tuyến tính đa biến cho thấy quy hoạch sử dụng đất thành phố Cần Tho bị ảnh hưởng 55,1\% bởi các nhóm yếu tố đura vào mô hình nghiên cứu. Theo kết quả nghiên cưu, có 5 nhóm yếu tố có ảnh hưởng tích cực đến quy hoạch sư dụng đất tại thành phố Cần Tho theo góc nhìn ngườ sử dưng đất với mức ý nghĩa thống kê là $1 \%$ (xếp theo mức độ tù mạnh đến yếu) gồm: nhóm yếu tố kinh tế, nhóm yếu tố môi truờng, nhóm các yếu tố khác, nhóm yếu tố xã họi, nhóm yếu tố thể chế, pháp lý.

\section{1. ĐẶT VẤN ĐỀ}

Thành phố Cần Thơ là đô thị loại 1, là đô thị hạt nhân của Đồng bằng sông Cửu Long. Phấn đâu đến 2030 thành phố Cần Thơ là đô thị sinh thái, văn minh, hiện đại mang đậm bản sắc văn hoá sông nước vùng Đồng bằng sông Cửu Long; là trung tâm của vùng về dịch vụ thương mại, du lịch, logistics, công nghiệp chế biến, nông nghiệp ứng dụng công nghệ cao, giáo dục và đào tạo, y tế chuyên sâu, khoa học công nghệ, văn hoá, thể thao (Bộ Chính trị, 2020). Với trọng trách này, thành phố Cần Thơ đã không ngừng phấn đất để đạt được các mục tiêu đề ra. Bên cạnh đó, công tác quy hoạch và phát triển đô thị được thực hiện tương đối tốt, thành phố là 1 trong 6 đô thị trọng điểm thực hiện Đề án phát triển các đô thị Việt Nam ứng phó với biến đổi khí hậu và được 
vinh danh, nhận "Chứng chỉ ASEAN thành phố tiềm năng để trở thành thành phố bền vững về môi trường lần thứ 3 về không khí sạch" (Ban Kinh tế Trung ương, 2020).

Tuy nhiên trong thời gian qua, kinh tế thành phố phát triển chưa tương xứng với tiềm năng, lợi thế; chưa thực sự là trung tâm động lực của vùng Đồng bằng sông Cửu Long. Cơ cấu kinh tế chuyển dịch chậm, nhất là ngành công nghiệp; phát triển của ngành dịch vụ chưa tạo ra được sự đột phá, chưa trở thành trung tâm dịch vụ lớn, đa ngành của vùng; nông nghiệp chưa phát huy hết tiềm năng, lợi thế, chưa thể hiện rõ vai trò sản xuất nông nghiệp theo hướng hiện đại. Công tác quy hoạch, quản lý quy hoạch, nhất là quy hoạch sử dụng đất, quy hoạch đô thị còn yếu kém, thiếu bền vững (Bộ Chính trị, 2020). Việc nghiên cứu xác định các yếu tố ảnh hưởng đến quy hoạch, kế hoạch sử dụng đất đã được nhiều nhà nghiên cứu thực hiện từ rất lâu, tiêu biểu như: Lương Văn Hinh và ctv. (2003, trích dẫn bởi Lê Anh Tuấn \& Võ Quang Minh, 2015) đã cho thấy sự tác động của các yếu tố về điều kiện tự nhiên, kinh tế xã hội tác động mạnh mẽ đến quy hoạch sử dụng đất; Lê Anh Tuấn và Võ Quang Minh (2015) xác định được 8 yếu tố (tái định cư cho người bị thu hồi đất; số liệu điều tra, thu thập; khí hậu, thời tiết; đào tạo nghề, việc làm; khả năng nguồn vốn; vị trí; mục tiêu lập quy hoạch và yếu tố thị trường, nhu cầu phát triển của địa phương) tác động chủ đạo đến hiệu quả quy hoạch sử dụng đất. Trong nghiên cứu này, mô hình phân tích nhân tố khám phá (exploratory factor analysis - EFA) và mô hình hồi quy tuyến tính đa biến được sử dụng nhằm xác định các yếu tố ảnh hưởng đến quy hoạch sử dụng đất tại thành phố Cần Thơ theo góc nhìn người sử dụng đất.

\section{PHƯONG PHÁP NGHIÊN CỨU}

\subsection{Giả thuyết}

Nghiên cứu dựa trên kết quả các nghiên cứu của Lê Anh Tuấn và Võ Quang Minh (2015) và đặc điểm của vùng nghiên cứu, mô hình nghiên cứu đã được xây dựng (Hình 1 ). Giả thuyết rằng tất cả các nhóm yếu tố kinh tế (KT), nhóm yếu tố xã hội $(\mathrm{XH})$, nhóm yếu tố môi trường (MT), nhóm yếu tố thể chế, pháp lý (PL), nhóm các yếu tố khác $(\mathrm{K})$ có ảnh hưởng đến quy hoạch sử dụng đất trên địa bàn thành phố Cần Thơ.

\begin{tabular}{|c|c|c|c|c|}
\hline \multicolumn{5}{|c|}{ QUY HOẠCH SỬ DỤNG ĐÁT TPCT } \\
\hline$\hat{\mathrm{\nu}}$ & † & 宓 & i & 仓 \\
\hline 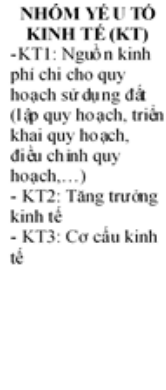 & 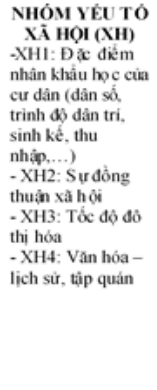 & 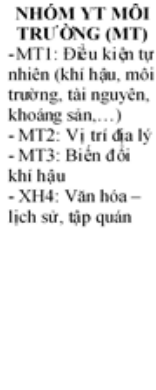 & 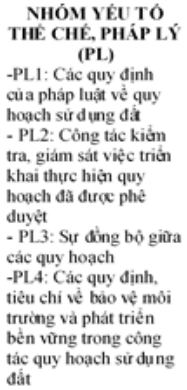 & 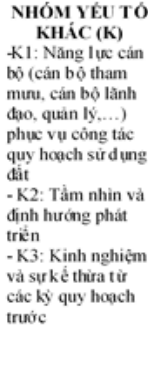 \\
\hline
\end{tabular}

Hình 1. Mô hình nghiên cứu

\subsection{Phương pháp}

\subsubsection{Phuong pháp thu thập số liệu}

Số liệu thu thập bao gồm: (1) số liệu thứ cấp từ báo cáo kết quả thực hiện quy hoạch sử dụng đất thành phố Cần Thơ giai đoạn 2010 - 2015 và 2015 2020 làm cơ sở đánh giá những kết quả đạt được cũng như những tác động trong công tác quy hoạch sử dụng đất ở thành phố Cần Thơ; (2) số liệu sơ cấp từ điều tra phỏng vấn 100 người sử dụng đất trong vùng quy hoạch đô thị (người sử dụng đất trong nghiên cứu được hiểu là người dân có đất trong vùng quy hoạch, đã có dự án và đang thực hiện). Hair et al. (2006) cho rằng để sử dụng phân tích nhân tố khám phá (exploratory factor analysis - EFA), kích thước mẫu tối thiểu phải là 50 , tốt hơn là 100 và tỷ lệ quan sát/biến đo lường là $5: 1$. Trong nghiên cứu này có 17 biến đo lường ứng với 85 quan sát tối thiểu, nghiên cứu đã thực hiện 100 mẫu khảo sát. Trong nghiên cứu này sử dụng thang đo Likert từ 1 đến 5 để thiết kế bảng câu hỏi về đo lường mức độ ảnh hưởng của các yếu tố ảnh hưởng quy hoạch sử dụng đất thành phố Cần Thơ, trong đó $1=$ Rất không đồng ý, $2=$ Không đồng ý, 3 = Trung hòa (Phân vân), 4 = Đồng ý, và 5 = Rất đồng ý (Likert, 1932). Người trả lời được yêu cầu chỉ chọn một phương án cho mỗi câu hỏi. Dũ liệu sơ cấp sau khi thu thập được tổng hợp bằng Excel và sử dụng SPSS phân tích. 


\subsubsection{Phuơng pháp phân tích nhân tố khám phá (EFA)}

Nghiên cứu sử dụng phân tích yếu tố khám phá (EFA) để xác định mối quan hệ cơ bản giữa các yếu tố (Norris et al., 2010). Các yếu tố được kiểm định giá trị thang đo, thực hiện sau khi đánh giá độ tin cậy của thang đo bằng hệ số Cronbach's Alpha và loại đi các biến không đảm bảo độ tin cậy (Cronbach, 1951). Giá trị alpha tối đa 0,90 đã được đề xuất (Streiner, 2003). Dữ liệu sẽ được chấp nhận khi Tổng tương quan $>0,3$ (Nunnally \& Bernstein, 1994; Hair et al., 1998).

- Thông qua trị số KMO (Kaiser-MeyerOlkin) để xem xét sự thích hợp của phân tích nhân tố. Điều kiện các biến chỉ được chấp nhận khi KMO nằm trong khoảng [0,5-1].

- Thông qua Kiểm định Barlett's với mức ý nghĩa $($ Sig. $<0,05)$ để đảm bảo các yếu tố có mối tương quan với nhau trong tổng thể.

- Hệ số Eigenvalue có giá trị > 1 để đảm bảo các nhóm yếu tố có sự khác biệt.

- Tổng phương sai giải thích: thang đo chỉ được chấp nhận khi tổng phương sai giải thích (Total variance explained) $>50 \%$.

Cuối cùng là xây dựng mô hình hồi quy đa biến để xác định hệ số mức độ ảnh hưởng của các yếu tố đối với quy hoạch sử dụng đất đai.

Theo Bliss (1934), mô hình hồi quy gồm biến phụ thuộc và biến giải thích như sau:

$$
Y_{i}^{*}=\beta_{0}+\sum_{j=1}^{k} \beta_{j} X_{i j}+u_{i}
$$

Trong đó $Y_{i}^{*}$ chưa biết, được gọi là biến ẩn. Trong nghiên cứu này, nhằm xác định các yếu tố ảnh hưởng đến việc thực hiện quy hoạch sử dụng đất. Mô hình được thiết lập như sau:

$$
Y=B_{0}+B_{1} X_{1}+B_{2} X_{2}+B_{3} X_{3}+\ldots
$$

Trong đó: đất

Y là biến phụ thuộc thể hiện quy hoạch sử dụng

$\mathrm{X}$ là biến độc lập thể hiện các yếu tố ảnh hưởng đến việc thực hiện quy hoạch sử dụng đất

$\mathrm{B}$ là các tham số hồi quy

\section{KẾT QUẢ VÀ THẢO LUẬN}

\subsection{Thực trạng công tác quy hoạch sử dụng đất} ở thành phố Cần Thơ trong thời gian qua

Thành phố đã xây dựng ba đồ án quy hoạch lớn và được chính phủ phê duyệt bao gồm: Quy hoạch tổng thể phát triển kinh tế xã hội thành phố Cần Thơ đến 2020, tầm nhìn đến 2030; Quy hoạch chung xây dựng thành phố Cần Thơ đến năm 2030, tầm nhìn đến 2050 và Quy hoạch sử dụng đất thành phố Cần Thơ đến năm 2020 và kế hoạch sử dụng đất 05 năm kỳ đầu (2011-2015), kế hoạch sử dụng đất 05 năm kỳ cuối (2016-2020). Qua đó, nhiều công trình dự án trên địa bàn được thực hiện góp phần phát triển kinh tế xã hội của thành phố thời kỳ 2010 - 2020. Công tác quản lý nhà nước về quy hoạch sử dụng đất đai cơ bản ngày càng hoàn thiện và đạt được nhiều kết quả tích cực. Tuy nhiên, vẫn còn tồn tại nhiều bất cập, khó khăn trong thực tế như:

Một là, việc thực hiện kế hoạch sử dụng đất không đạt với chỉ tiêu kế hoạch đề ra (Bảng 1). Diện tích đất nông nghiệp xu hướng giảm nhưng vẫn chưa đảm bảo theo kế hoạch, đến 2020 vẫn còn cao hơn kế hoạch được duyệt 4.618,51 ha. Diện tích đất phi nông nghiệp xu hướng tăng nhưng vẫn chưa đảm bảo theo kế hoạch, đến 2020 vẫn thấp hơn kế hoạch 4.494,74 ha. Diện tích đất chưa sử dụng xu hướng giảm nhưng việc thực hiện cũng chưa đảm bảo theo kế hoạch, kế hoạch đến năm 2020 sẽ đưa 86,51 ha đất chưa sử dụng vào sử dụng $100 \%$ (đồng nghĩa kế hoạch đến 2020 không còn đất chưa sử dụng) tuy nhiên đến thời điểm thống kê thì vẫn còn 20,51 ha đất chưa sử dụng.

\section{Bảng 1. So sánh việc thực hiện kế hoạch sử dụng 03 nhóm đất chính 2010 - 2020}

\begin{tabular}{lrrrrrrrr}
\hline \multirow{2}{*}{ Nhóm đất } & \multicolumn{2}{c}{ Diện tích 2010 (ha) } & \multicolumn{2}{c}{ Diện tích 2015 (ha) } & \multicolumn{2}{c}{ Diện tích 2020 (ha) } & \multicolumn{2}{c}{ tăng (+), } \\
\cline { 2 - 8 } & Kế hoạch & Thực hiện & Kế hoạch & Thực hiện & Kế hoạch & Thực hiện & giảm (-) \\
\hline (1) & $(2)$ & $(3)$ & $(4)$ & $(5)$ & $(6)$ & $(7)$ & $(8)$ \\
\hline Đất nông nghiệp & $108.494,34$ & $115.319,61$ & 110.706 & $115.419,52$ & 109.690 & $114.308,51$ & - \\
Đất phi nông nghiệp & $31.447,84$ & $25.378,24$ & 30.057 & $28.390,26$ & 34.207 & $29.712,26$ & + \\
Đất chưa sử dụng & 268,89 & 197,07 & 132 & 86,51 & 0 & 20,51 & - \\
\hline
\end{tabular}

Nguồn: Sở Tài nguyên và Môi truờng thành phố Cần Tho, 2020.

Hai là, việc phê duyệt kế hoạch sử dụng đất chậm so với quy định, dần đến việc giao đất, cho thuê đất, cho phép chuyển mục đích sử dụng đất theo kế hoạch bị ảnh hưởng. Công tác lập, thẩm định, phê 
duyệt quy hoạch chưa phù hợp về thời gian, nội dung với quy hoạch sử dụng đất, quy hoạch hạ tầng kỹ thuật và hạ tầng xã hội. Cụ thể, quy hoạch sử dụng đất đai thành phố Cần Thơ đến năm 2020 và kế hoạch sử dụng đất kỳ đầu (2010-2015) được chính phủ phê duyệt năm 2013 (theo Nghị quyết số 57/NQ-CP ngày 04/5/2013) chậm ba năm; kế hoạch sử dụng đất kỳ cuối (2016-2020) chính phủ phê duyệt năm 2018 (theo Nghị quyết số 52/NQ-CP ngày $10 / 5 / 2018$ ) chậm hai năm.

Ba là, thiếu đồng bộ trong sử dụng đất, không đồng nhất các chỉ tiêu thống kê các loại đất, pháp lý thường thay đổi dẫn đến việc các quy hoạch phải điều chỉnh, bổ sung; chất lượng quy hoạch còn thấp, thiếu tính khả thi, không đảm bảo nguồn lực đất đai để thực hiện. Cụ thể, so sánh hiện trạng sử dụng đất năm 2020, năm 2015 và năm 2010 (cột 3,5,7, Bảng 1). Tổng diện tích tự nhiên năm 2020 tăng so với 2015 là 144 ha, tăng 3.145 ha so với 2010. Nguyên nhân chủ yếu có sự khác biệt về tổng diện tích tự nhiên là do sự thay đổi trong việc phân loại các loại đất theo mục đích sử dụng năm 2010 (sử dụng theo Luật Đất đai 2003), năm 2015 (sử dụng theo Luật Đất đai 2013) và do có sự điều chỉnh địa giới hành chính (theo Nghị quyết 893/NQ-UBNDTVQH14 ngày 11/02/2020). Qua Bảng 1 , diện tích nhóm đất nông nghiệp xu hướng giảm; diện tích nhóm đất phi nông nghiệp tăng; diện tích đất chưa sử dụng giảm. Xu hướng biến động đất đai thành phố Cần Thơ đang chuyển dịch theo hướng cơ cấu kinh tế tăng dần tỷ trọng công nghiệp - thương mại - dịch vụ và giảm dần tỷ trọng nông nghiệp. Tuy nhiên, cơ cấu đất nông nghiệp hiện nay vẫn chiếm tỷ trọng cao gần $80 \%$ diện tích tự nhiên.

Bốn là, thiếu tính đồng bộ và chưa có sự thống nhất giữa Luật Đất đai năm 2013 và các văn bản pháp luật khác có liên quan như Luật Đấu thầu năm 2013, Luật Nhà ở năm 2014, Luật Đầu tư năm 2014. Đơn cử như trong trường hợp dự án bị chấm dứt hoạt động thì việc xử lý vấn đề đất đai, tài sản gắn liền với đất theo quy định tại Điều 64 Luật Đất đai năm 2013 và Điều 46, 48 Luật Đầu tư năm 2014 chưa có sự đồng bộ giữa quy định gia hạn tiến độ sử dụng đất. Quy định về đấu thầu dự án có sử dụng đất, đấu giá quyền sử dụng đất, chỉ định chủ đầu tư giữa Luật Đất đai năm 2013 (điều 118 về các trường hợp đấu giá quyền sử dụng đất và không đấu giá quyền sử dụng đất) chưa thống nhất với Luật Đấu thầu năm 2013 và Luật Nhà ở năm 2014. Thẩm quyền chấp thuận sự cần thiết phải thu hồi đất và thẩm quyền quyết định chủ trương đầu tư, quyết định dự án đầu tư giữa Điều 62 Luật Đất đai năm 2013 và Luật Đầu tư năm 2014 chưa thống nhất.

\subsection{Các yếu tố được đề xuất tham gia mô hình}

Có nhiều yếu tố ảnh hưởng đến quy hoạch sử dụng đất. Theo Lương Văn Hinh và ctv. (2003, trích dần bởi Lê Anh Tuấn \& Võ Quang Minh, 2015), các yếu tố về điều kiện tự nhiên, kinh tế xã hội tác động mạnh mẽ đến quy hoạch sử dụng đất. Lề Anh Tuấn và Võ Quang Minh (2015) xác định được 8 yếu tố (tái định cư cho người bị thu hồi đất; số liệu điều tra, thu thập; khí hậu, thời tiết; đào tạo nghề, việc làm; khả năng nguồn vốn; vị trí; mục tiêu lập quy hoạch và yếu tố thị trường, nhu cầu phát triển của địa phương) tác động chủ đạo đến hiệu quả quy hoạch sử dụng đất đai. Trong nghiên cứu đã kê thừa kết quả các nghiên cứu đồng thời bổ sung và điều chỉnh một số nhóm yếu tố được các chuyên gia cho rằng phù hợp với đặc trưng của thành phố Cần Thơ. Có 5 nhân tố độc lập với 17 biến quan sát được chọn lựa để nghiên cứu (Bảng 2).

Bảng 2. Nhân tố ảnh hưởng đến quy hoạch sử dụng đất đai ở thành phố Cần Thơ

\begin{tabular}{|c|c|c|}
\hline Nhóm yếu tố & Ký hiệu & Các tiêu chí đánh giá \\
\hline \multirow{3}{*}{ Kinh tế (KT) } & KT1 & $\begin{array}{l}\text { Nguồn kinh phí chi cho quy hoạch sử dụng đất (lập quy hoạch, triển } \\
\text { khai quy hoạch, điều chỉnh quy hoạch,...) }\end{array}$ \\
\hline & KT2 & Tăng trưởng kinh tế \\
\hline & KT3 & Cơ cấu kinh tế \\
\hline \multirow{4}{*}{ Xã hội (XH) } & XH1 & $\begin{array}{l}\text { Đặc điểm nhân khẩu học của cư dân (dân số, trình độ dân trí, sinh kế, } \\
\text { thu nhập,...) }\end{array}$ \\
\hline & $\mathrm{XH} 2$ & Sự đồng thuận xã hội \\
\hline & XH3 & Tốc độ đô thị hóa \\
\hline & XH4 & Văn hóa - lịch sử, phong tục, tập quán \\
\hline \multirow{3}{*}{ Môi trường (MT) } & MT1 & Điều kiện tự nhiên (khí hậu, môi trường, tài nguyên, khoáng sản,...) \\
\hline & MT2 & Vị trí địa lý \\
\hline & MT3 & Biến đổi khí hậu \\
\hline Thể chế, pháp lý (PL) & PL1 & Các quy định của pháp luật về quy hoạch sử dụng đất \\
\hline
\end{tabular}




\begin{tabular}{lll}
\hline Nhóm yếu tố & Ký hiệu & Các tiêu chí đánh giá \\
\hline PL2 & $\begin{array}{l}\text { Công tác kiếm tra, giám sát việc triến khai thực hiện quy hoạch đã được } \\
\text { phê duyệt }\end{array}$ \\
PL3 & $\begin{array}{l}\text { Sự đồng bộ giữa các quy hoạch } \\
\text { Các quy định, tiêu chí về bảo vệ môi trường và phát triển bền vững } \\
\text { trong công tác quy hoạch sử dụng đất }\end{array}$ \\
\hline PL4 & K1 & $\begin{array}{l}\text { Năng lực cán bộ (cán bộ tham mưu, cán bộ lãnh đạo, quản lý,...) phục } \\
\text { vụi công tác quy hoạch sử dụng đất }\end{array}$ \\
Khác $(\mathbf{K})$ & Tầm nhìn và định hướng phát triển \\
& K3 & Kinh nghiệm và sự kế thừa từ các kỳ quy hoạch trước \\
\hline
\end{tabular}

3.3. Phân tích nhân tố khám phá EFA và mô hình hồi quy tuyến tính đa biến

\subsubsection{Kiểm tra độ tin cậy Cronbach's alpha}

Theo Nunnally and Bernstein (1994) và Hair et al. (1998), điều kiện để dữ liệu đảm bảo độ tin cậy khi phân tích thì phải thỏa điều kiện hệ số Cronbach's Alpha nằm trong khoảng $0,6-0,95$ và có hệ số tương quan biến tổng (Corrected Item-Rest Correlation) lớn hơn 0,3 . Kết quả kiểm tra độ tin cậy thang đo các biến độc lập (Bảng 3).

\section{Bảng 3. Kết quả kiểm định độ tin cậy thang đo biến độc lập}

Ký hiệu Các tiêu chí đánh giá

$\begin{array}{rr}\text { Hệ số } & \text { Alpha } \\ \text { Tương } & \text { Nếu loại } \\ \text { Quan với } & \text { Một } \\ \text { Biến tổng } & \text { Biến }\end{array}$

Nhóm biến kinh tế (KT)

\begin{tabular}{|c|c|c|c|}
\hline & Nhóm biến kinh tế (KT) & & 0,869 \\
\hline KT1 & $\begin{array}{l}\text { Nguồn kinh phí chi cho quy hoạch sử dụng đất (lập quy hoạch, } \\
\text { triển khai quy hoạch, điều chỉnh quy hoạch,...) }\end{array}$ & 0,760 & 0,815 \\
\hline KT2 & Tăng trưởng kinh tế & 0,787 & 0,782 \\
\hline \multirow[t]{2}{*}{$\underline{\text { KT3 }}$} & Cơ cấu kinh tế & 0,717 & 0,850 \\
\hline & Nhóm biến xã hội (XH) & & 0,815 \\
\hline XH1 & $\begin{array}{l}\text { Đặc điểm nhân khẩu học của cư dân (dân số, trình độ dân trí, sinh } \\
\text { kế, thu nhập,...) }\end{array}$ & 0,573 & 0,796 \\
\hline $\mathrm{XH} 2$ & Sự đồng thuận xã hội & 0,652 & 0,761 \\
\hline XH3 & Tốc độ đô thị hóa & 0,656 & 0,760 \\
\hline \multirow[t]{2}{*}{ XH4 } & Văn hóa - lịch sử, phong tục, tập quán & 0,673 & 0,750 \\
\hline & Nhóm biến môi trường (MT) & & 0,762 \\
\hline$\overline{\text { MT1 }}$ & Điều kiện tự nhiên (khí hậu, môi trường, tài nguyên, khoáng sản,...) & 0,596 & 0,736 \\
\hline MT2 & Vị trí địa lý & 0,588 & 0,713 \\
\hline \multirow[t]{2}{*}{ MT3 } & Biến đổi khí hậu & 0,674 & 0,601 \\
\hline & Nhóm biến thể chế, pháp lý (PL) & & 0,770 \\
\hline$\overline{\text { PL1 }}$ & Các quy định của pháp luật về quy hoạch sử dụng đất & 0,553 & 0,727 \\
\hline PL2 & $\begin{array}{l}\text { Công tác kiểm tra, giám sát việc triển khai thực hiện quy hoạch đã } \\
\text { được phê duyệt }\end{array}$ & 0,698 & 0,644 \\
\hline PL3 & Sự đồng bộ giữa các quy hoạch & 0,507 & 0,746 \\
\hline \multirow[t]{2}{*}{ PL4 } & $\begin{array}{l}\text { Các quy định, tiêu chí về bảo vệ môi trường và phát triển bền } \\
\text { vững trong công tác quy hoạch sử dụng đất }\end{array}$ & 0,557 & 0,733 \\
\hline & Nhóm nhân tố khác (K) & & 0,737 \\
\hline K1 & $\begin{array}{l}\text { Năng lực cán bộ (cán bộ tham mưu, cán bộ lãnh đạo, quản lý,...) } \\
\text { phục vụ công tác quy hoạch sử dụng đất }\end{array}$ & 0,615 & 0,585 \\
\hline $\mathrm{K} 2$ & Tầm nhìn và định hướng phát triển & 0,516 & 0,706 \\
\hline $\mathrm{K} 3$ & Kinh nghiệm và sự kế thừa từ các kỳ quy hoạch trước & 0,556 & 0,658 \\
\hline
\end{tabular}

Qua Bảng 3, các biến độc lập đều có hệ số Cronbach's Alpha nằm trong khoảng $[0,6-0,95]$ và có hệ số tương quan biến tổng lớn hơn 0,3 . Điều này chứng tỏ dữ liệu đảm bảo độ tin cậy để tiếp tục phân tích thêm. 


\subsubsection{Phân tích nhân tố khám phá EFA}

Kết quả phân tích mô hình nghiên cứu (Bảng 4) cho thấy các hệ số tải nhân tố đều lớn hơn 0,3 , các nhân tố trong (Bảng 4) là phù hợp và được sử dụng cho mô hình hồi quy đa biến phân tích các nhân tố ảnh hưởng đến Quy hoạch sử dụng đất đai cho phát triển bền vững đối với góc nhìn của người sử dụng đất trong vùng quy hoạch.

Bảng 4. Kiểm định Kaiser-Meyer-Olkin (KMO) và Bartlett's Test

\begin{tabular}{|c|c|c|c|c|c|}
\hline \multirow{2}{*}{ Biến quan sát } & \multicolumn{5}{|c|}{ Thành phần } \\
\hline & 1 & 2 & 3 & 4 & 5 \\
\hline XH4 & 0,820 & & & & \\
\hline $\mathrm{XH} 2$ & 0,814 & & & & \\
\hline XH3 & 0,814 & & & & \\
\hline XH1 & 0,752 & & & & \\
\hline PL2 & & 0,894 & & & \\
\hline PL1 & & 0,791 & & & \\
\hline PL4 & & 0,721 & & & \\
\hline PL3 & & 0,642 & & & \\
\hline KT2 & & & 0,913 & & \\
\hline KT1 & & & 0,897 & & \\
\hline KT3 & & & 0,859 & & \\
\hline MT3 & & & & 0,849 & \\
\hline MT2 & & & & 0,813 & \\
\hline MT1 & & & & 0,801 & \\
\hline K1 & & & & & 0,832 \\
\hline K3 & & & & & 0,792 \\
\hline $\mathrm{K} 2$ & & & & & 0,791 \\
\hline Hệ số Eigenvalue & 2,998 & 2,584 & 2,324 & 2,069 & 1,777 \\
\hline Phương sai giải thích & 17,636 & 15,200 & 13,672 & 12,170 & 10,455 \\
\hline Kaiser-Meyer-Olkin & & & & & 0,645 \\
\hline Bartlett's Test & & & & & 0,000 \\
\hline
\end{tabular}

Qua Bảng 4, trị số KMO là 0,645 thỏa điều kiện $\mathrm{KMO}$ nằm trong khoảng [0,5-1]. Điều này cho thấy các yếu tố đề xuất thích hợp đề thực hiện phân tích nhân tố EFA. Kết quả kiểm định Barlett's với mức ý nghĩa 0,000 thỏa điều kiện (sig. $<0,05)$, điều này đảm bảo các yếu tố có mối tương quan với nhau trong tổng thể. Hệ số Eigenvalue của mỗi nhóm có giá trị lớn hơn 1 , điều này đảm bảo các nhóm yếu tố có sự khác biệt. Tổng phương sai giải thích (total variance explained) lớn hơn $50 \%$, do vậy thang đo các biến được chấp nhận.

\subsubsection{Các nhân tố ảnh hưởng đến Quy hoạch sư dụng đất đai}

Nghiên cứu sử dụng mô hình hồi quy đa biến để xác định hệ số mức độ ảnh hưởng của các yếu tố đối với quy hoạch sử dụng đất đai. Kết quả phân tích mô hình hồi quy đa biến (Bảng 5).

Bảng 5. Các nhân tố ảnh hưởng đến Quy hoạch sử dụng đất đai

\begin{tabular}{|c|c|c|c|c|c|c|}
\hline \multirow{2}{*}{ Nhân tố } & \multicolumn{2}{|c|}{ Chưa chuẩn hóa } & \multirow{2}{*}{ Beta chuẩn hóa } & \multirow[b]{2}{*}{$\mathbf{t}$} & \multirow{2}{*}{ Sig. } & \multirow[b]{2}{*}{ VIF } \\
\hline & B & $\overline{\text { Std, Error }}$ & & & & \\
\hline Hằng Số & $1,161 \mathrm{E}-16$ & 0,069 & & 0,000 & 1,000 & \\
\hline PL & 0,233 & 0,069 & 0,233 & 3,376 & 0,001 & 1,000 \\
\hline $\mathrm{XH}$ & 0,257 & 0,069 & 0,257 & 3,726 & 0,000 & 1,000 \\
\hline $\mathrm{K}$ & 0,338 & 0,069 & 0,338 & 4,886 & 0,000 & 1,000 \\
\hline MT & 0,373 & 0,069 & 0,373 & 5,391 & 0,000 & 1,000 \\
\hline KT & 0,422 & 0,069 & 0,422 & 6,102 & 0,000 & 1,000 \\
\hline \multicolumn{3}{|l|}{$\overline{\mathrm{R}^{2}}$} & \multicolumn{2}{|c|}{0,551} & & \\
\hline \multicolumn{3}{|c|}{ Durbin-Watson } & \multicolumn{2}{|c|}{2,342} & & \\
\hline \multicolumn{3}{|c|}{ ANOVA với kiểm định $\mathrm{F}$} & \multicolumn{2}{|c|}{0,000} & & \\
\hline
\end{tabular}

Qua Bảng 5 , hệ số $\mathrm{R}^{2}=0,551$ có nghĩa là mô hình có thể giải thích được $55,1 \%$ cho tổng thể về mối quan hệ giữa Quy hoạch sử dụng đất đai và các nhân tố được đưa ra theo quan điểm của người sử 
dụng đất. Kết quả kiểm định Durbin-Watson cho trị số bằng 2,342 gần với hệ số 2,0 và trong khoảng từ 1-3 chứng tỏ không có tương quan chuỗi bậc 1 trong mô hình (Hoàng Trọng \& Chu Nguyễn Mộng Ngọc, 2008). Kết quả phân tích ANOVA với kiểm định $\mathrm{F}$ sử dụng trong bảng phân tích phương sai là phép kiểm định giả thuyết về độ phù hợp của mô hình hồi quy tuyến tính, cho thấy giá trị Sig. $=0,000$ nên mô hình hồi quy tuyến tính đã xây dựng là phù hợp, mô hình hồi quy đưa ra tương đối phù hợp với mức ý nghĩa $1,0 \%$.

Kết quả nghiên cứu cho thấy các nhân tố đều có hệ số hồi quy $\beta>0$ nên các nhân tố này có ảnh hưởng cùng chiều với Quy hoạch sử dụng đất đai. Dựa trên mức ý nghĩa (sig.) của từng nhân tố, cả 5 nhân tố có tác động lên quy hoạch sử dụng đất đai theo đánh giá của người sử dụng đất có đất trong vùng quy hoạch đó là: nhóm biến kinh tế $(\mathrm{KT})$, nhóm biến xã hội $(\mathrm{XH})$, nhóm biến môi trường (MT), nhóm biến thể chế, pháp lý (PL), nhóm các yếu tố khác $(\mathrm{K})$ với mức ý nghĩa thống kê là $1 \%$.

Mô hình nghiên cứu được viết lại như sau:

$$
\begin{aligned}
& \text { QHSDĐ }=0,233 \cdot \mathrm{PL}+0,257 \cdot \mathrm{XH}+0,338 \cdot \mathrm{K}+ \\
& \text { 0,373.MT+ 0,422.KT }
\end{aligned}
$$

Biểu đồ trọng số yếu tố ảnh hưởng quy hoạch sử dụng đất đai thành phố Cần Thơ dưới góc nhìn người sử dụng đất (Hình 1).

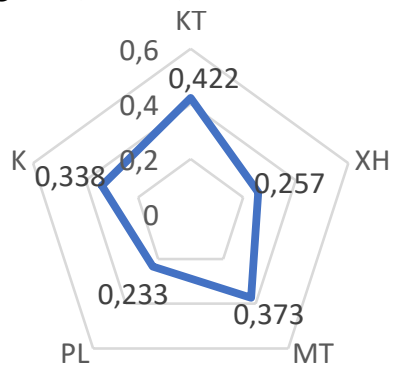

\section{Hình 1. Biểu đồ trọng số yếu tố ảnh hưởng quy hoạch sử dụng đất đai thành phố Cần Thơ theo góc nhìn người sử dụng đất}

Đối với người sử dụng đất có đất trong vùng quy hoạch, các nhóm nhân tố được đưa ra đều có tác động thuận chiều lên quy hoạch sử dụng đất đai (hệ số $\beta>0$ ). Qua Hình 1, yếu tố ảnh hường mạnh nhất là nhóm yếu tố kinh tế (hệ số $\beta=0,422$ ), thứ 2 là nhóm yếu tố môi trường (hệ số $\beta=0,373$ ), thứ 3 là nhóm yếu tố khác (hệ số $\beta=0,338$ ), thứ 4 là nhóm yếu tố xã hội (hệ số $\beta=0,257$ ), cuối cùng là nhóm yếu tố thể chế, pháp lý (hệ số $\beta=0,233$ ).

\section{HÀM Ý CHÍNH SÁCH}

Kết quả nghiên cứu này đã khẳng định thêm cho kết quả nghiên cứu đối với góc nhìn của cán bộ chuyên môn trong lĩnh vực quy hoạch sử dụng đất đai. Tuy nhiên ở góc nhìn của người sử dụng đất có đất trong vùng quy hoạch có sự khác biệt khi nhóm nhân tố kinh tế với các vấn đề nguồn kinh phí chi cho quy hoạch sử dụng đất (lập quy hoạch, triển khai quy hoạch, điều chỉnh quy hoạch), tăng trưởng kinh tế, cơ cấu kinh tế có ảnh hưởng mạnh hơn những nhân tố khác. Đồng thời đối với góc nhìn người sử dụng đất có đất trong vùng quy hoạch, thì nhóm nhân tố khác $(\mathrm{K})$ (gồm năng lực, tầm nhìn và kinh nghiệm của cán bộ) cũng có ảnh hưởng đối với quy hoạch sử dụng đất thành phố Cần Thơ. Đây là nhóm nhân tố có ảnh hưởng cùng chiều mạnh thứ 3 lên đến quy hoạch sử dụng đất đai thành phố Cần Thơ theo đánh giá của người dân trong vùng quy hoạch, có nghĩa là khi năng lực cán bộ (cán bộ tham mưu, cán bộ lãnh đạo, quản lý) phục vụ công tác quy hoạch sử dụng đất tốt, có tầm nhìn và định hướng phát triển giỏi, hoặc với kinh nghiệm và sự kế thừa từ các kỳ quy hoạch trước càng tốt thì quy hoạch sử dụng đất đai sẽ được thực hiện hiệu quả.

Một số giải pháp hoàn thiện cơ chế quản lý nhà nước về quy hoạch sử dụng đất đai hướng đến phát triển bền vững như sau:

Một là cần tổng kết, đánh giá việc thực hiện và đề xuất sửa đổi, bổ sung Luật Đất đai năm 2013. Việc sửa đổi, bổ sung Luật Đất đai năm 2013 phải khắc phục được các vướng mắc, bất cập, bảo đảm sự thống nhất giữa các luật có liên quan; trường hợp các luật khác có quy định về đất đai thì phải thống nhất với Luật Đất đai; đổi mới chính sách về quy hoạch theo hướng hiệu quả, bền vững.

Hai là tiếp tục rà soát, tổ chức lập quy hoạch sử dụng đất thành phố Cần Thơ giai đoạn 2020 - 2030, kế hoạch sử dụng đất 05 năm kỳ đầu 2020 - 2025 phù hợp quy hoạch, kế hoạch sử dụng đất cấp quốc gia. Việc triển khai lập quy hoạch, kế hoạch sử dụng đất các cấp theo quy định của Luật Quy hoạch, Luật sửa đổi, bổ sung một số điều của 37 luật liên quan đến quy hoạch. Cần triển khai lập quy hoạch đồng bộ quy hoạch đô thị, khẩn trương lập các quy hoạch phân khu, quy hoạch chi tiết theo quy định;

Ba là lập kế hoạch đầu tư và đầu tư đồng bộ giữa hệ thống hạ tầng kỹ thuật, hạ tầng xã hội với phát triển nhà ở, công trình thương mại dịch vụ và công trình khác theo quy hoạch được duyệt

Bốn là thường xuyên tổ chức thanh tra, kiểm tra việc chấp hành các quy định của pháp luật liên quan đến quy hoạch sử dụng đất đai để kịp thời xử lý và 
chấn chỉnh. rà soát các quy hoạch, kế hoạch sử dụng đất đã quá thời hạn thực hiện, có biện pháp xử lý dứt điểm để bảo đảm quyền lợi của người sử dụng đất và hiệu quả sử dụng đất. Bên cạnh đó, cần tăng cường thông tin, bảo đảm tính công khai, minh bạch, dễ tiếp cận thông tin, đăng tải hồ sơ điều chỉnh quy hoạch đô thị trên trang thông tin điện tử của cơ quan có thẩm quyền thẩm định để xin ý kiến cộng đồng dân cư trước khi thẩm định hoặc phê duyệt. Cơ quan có trách nhiệm lập quy hoạch có trách nhiệm công bố, công khai ý kiến đóng góp và việc tiếp thu, giải trình các ý kiến đóng góp này. Khuyến khích và tạo điều kiện cho tổ chức, cá nhân, tổ chức xã hội - nghề nghiệp tham gia phản biện xã hội đối với việc thực hiện chính sách, pháp luật quản lý nhà nước về quy hoạch sử dụng đât đai.

\section{KẾT LUẬN}

Nghiên cứu đã ứng dụng phân tích nhân tố khám phá (EFA) xác định được 5 nhóm yếu tố ảnh hưởng đến quy hoạch sử dụng đất thành phố Cần Thơ, bao gồm nhóm yếu tố kinh tế (KT), nhóm yếu tố môi trường (MT), nhóm yếu tố khác (K), nhóm yếu tố xã hội $(\mathrm{XH})$, nhóm yếu tố thể chế, pháp lý (PL). Kết quả phân tích của mô hình hồi quy tuyến tính đa biến cho thấy quy hoạch sử dụng đất thành phố Cần Thơ có thể được giải thích bởi 55,1\% sự biến động của 5 nhóm biến độc lập.

Tại thành phố Cần Thơ, nhóm nhân tố kinh tế (nguồn kinh phí thực hiện quy hoạch, tăng trưởng kinh tế và cơ cấu kinh tế) có ảnh hưởng nhiều nhất đến quy hoạch sử dụng đất thành phố Cần Thơ với đóng góp 42,2\%, theo quan điểm người sử dụng đất có đất trong vùng quy hoạch đối với nhóm nhân tố thể chế pháp lý (các quy định của pháp luật về quy hoạch sử dụng đất, công tác kiểm tra, giám sát việc triển khai thực hiện quy hoạch, sự đồng bộ giữa các quy hoạch, các quy định, tiêu chí về bảo vệ môi trường và phát triển bền vững) đóng góp $23,3 \%$ so với các yếu tố còn lại.

Kết quả nghiên cứu đã chỉ ra 04 vấn đề khó khăn và đề xuất 04 giải pháp trong quản lý quy hoạch sử dụng đất. Trong thời gian tới, để quy hoạch sử dụng đất thành phố Cần Thơ ngày một hiệu quả, nhà quản lý cần quan tâm yếu tố về kinh tế (bao gồm kinh phí lập, điều tra, khảo sát, thực hiện quy hoạch, tốc độ phát triển kinh tế, chuyển dịch cơ cấu kinh tế) trong việc quy hoạch sử dụng đất đai, bên cạnh đó cần quan tâm đẩy mạnh tuyên truyền cho người sử dụng đất về thể chế pháp lý để người dân có sự đồng tình cao trong việc thực hiện quy hoạch, tạo cơ chế giám sát và phản biện xã hội giúp người dân phát huy quyền làm chủ của chủ thể sử dụng đất. Đồng thời chú trọng đào tạo cán bộ làm công tác quy hoạch (nâng cao năng lực, tầm nhìn và kinh nghiệm thực tiễn của cán bộ).

\section{TÀI LIỆU THAM KHẢO}

Bliss, C. I. (1934). The method of probits. Science, 79(2), 38-39.

Ban Kinh tế Trung ương. (2020). Phát triển bền vững thành phố Cần Thơ đến năm 2030, tầm nhìn đến năm 2045. Kỷ yếu hội thảo tổng kết Nghị quyết 45NQ/TW của Bộ Chính trị 2020 (trang 151-164).

Bộ Chính trị. (2020). Nghị quyết số 59-NQ/TW ngày $05 / 8 / 2020$ về xây dựng và phát triển thành phố Cần Thơ đến năm 2030, tầm nhìn đến năm 2045.

Cronbach L. (1951). Coefficient alpha and the internal structure of tests. Psychomerika. 16, 297-334.

Hair, Jr. J. F., Anderson, R. E., Tatham R. L. \& Black W. C. (1998). Multivariate Data Analysis (5th ed.). New York: Macmillan Publishing Company.

Hair, J. F., Black, W.C., Babin, B.J., Anderson. RE. \& Tatham, RL. (2006). Multivariate data analysis (6th ed.). Upper Saddle River, NJ: Pearson University Press.

Hoàng Trọng \& Chu Nguyễn Mộng Ngọc. (2005). Phân tích dữ liệu nghiên cứu với SPSS. Nhà xuất bản Thống kê.

Likert, R. A. (1932). A technique for measurements a attitudes, Archives of Psychology.

Lê Anh Tuấn \& Võ Quang Minh. (2015). Phân tích những yếu tố ảnh hưởng đến thưc hiện quy hoạch, kế hoạch sử dụng đất thành phố Cần Thơ dưới sự hỗ trợ của GIS. Kỷ yếu hội nghị GIS toàn quốc 2015 (trang 643-647).

https://sj.ctu.edu.vn/q1/docgia/kyyeuhoinghitrong nuoc-2015/baibao-30971.html?page_current=5

Norris, M., Lecavalier, L. J \& Autism Dev Disord. (2010). Evaluating the Use of Exploratory Factor Analysis in Developmental Disability Psychological Research. Journal of Autism and Developmental Disorders, 40(1), 8-20.

Nunnally, J. C., \& Bernstein, I. H. (1994). Psychometric theory (3rd ed.). New York: McGraw-Hill.

Streiner, D. (2003). Starting at the beginning: an introduction to coefficient alpha and internal consistency. Journal of personality assessment, 80(1), 99-103.

Sở Tài nguyên và Môi trường thành phố Cần Thơ. (2020). Báo cáo kết quả thực hiện quy hoạch sử dụng đất 2010-2020 (Số 59/BC-STNMT). 